\title{
Study on Basic Technical Requirements for Vehicle Event Data Recorder
}

\author{
Yan YIN ${ }^{1, a}$, Jinhuan ZHANG ${ }^{2, b}$, Yongqin FENG ${ }^{3, c}$, Xiaorui ZHANG ${ }^{4, d}$, Lingyun \\ ZENG ${ }^{5, e}$ \\ 1,3,4,5 China National Institute of Standardization, Beijing, 100191, China \\ 2 Tsinghua University, Beijing, 100084, China \\ aemail: yiny@dpac.gov.cn, bemail: zhjh@tsinghua.edu.cn, 'email: fengyq@dpac.gov.cn, \\ demail: ${ }^{d}$ zhangxr@dpac.gov.cn, ${ }^{\mathrm{e}}$ email: zengly@dpac.gov.cn
}

Keywords: Vehicle Event Data Recorder; Technical Specifications; Technical Requirements

\begin{abstract}
In the current global market for auto products, vehicle event data recorder (EDR) is a new generation of vehicle safety feature, and is also another onboard safety feature expected to be popular in succession to SRS and ABS system. Some countries have now formulated the related administrative and guiding regulations on data collection, storage and recovery for the vehicles with an EDR. Through analyzing the development history of EDR technology in the EU and the US, this paper studies basic technical requirements for recording, management and format of EDR data in our country, and thus contributes to increasing the efficiency of traffic accident management, optimizing the vehicle structure and road design and improving the traffic environment.
\end{abstract}

\section{Introduction}

In recent years, the research on application of event data recorder (EDR) has become a hot trend across the whole world due to increasingly grim situation of road traffic safety and successful application of new automotive electronic technologies. Different from vehicle traveling data recorder, a device mainly used for recording basic traveling information such as vehicle speed, time and mileage, EDR can record not only such information, but also the information on image, voice, speed, acceleration, GPS position, track data, angle of turn, airbag, brake, clutch, engine RPM and lamp on/off that has been gathered before and after an event. It can also send a distress signal via wireless internet or an auto alarm to Information Center, and provide timely first-aid measures for the people injured in the accident.

$\mathrm{Xu}$ Yang, Zhang Baoping and Shen Hongqing designed a detection system to rapidly read the violation data from a traveling data recorder in a wireless way. By integrating a GPS chip and a GPRS chip to the hardware, this system endows the existing traveling data recorder with such functions as realtime positioning and wireless data uploading. [1] Jiang Feng chose a S3C2440 microprocessor to design the modules such as DAQ. Among them, the GPS module has a positioning error of $10 \mathrm{~m}$ and a speed error of $0.1 \mathrm{~m} / \mathrm{s}$, and uses the embedded Linux system to operate the software. [2] Li Zhihong developed a traveling data recorder with the positioning function, and elaborated the developed process of BootLoader and OEM abstraction layer (OAL). [3] Through a survey on application and research of EDR in the EU and the US, where the vehicle safety level is higher, Shen Ming, Chen Yuzhong, Lan Yanfei, Wang Yan and Xu Shucai have studied the application prospect and standardization route of event data recording technology in our country. [4] In China, there have been a lot of studies on traveling data recorder, but very few on EDR and even no studies on its basic technical specifications.

\section{Foreign specifications and requirements for EDR}

\section{The EU}

The EU is the region where vehicle traveling data recorder is used earliest and most successfully. At the end of 1969, the EC promulgated and implemented the (EEC) No. 543/69 directive, which 
specified technical features of a recorder that was a perfect substitution of traveling log, as well as its type approval, usage and testing method. In 1970, the paper-reel recorder began to be used. In July 2002, the EU promulgated the (EC) No. 1360/2002 directive, whose annexes mainly dealt with the structural and functional requirements of recorder and its record card, the installation, inspection, supervision and maintenance of recorder, the issue of record card, and the type approval of both recorder and record card. In addition, the appendixes of this directive stipulated in detail the structure, technical requirements, usage, test method and inspection and supervision rules of digital recorder, including provisions on database, technical conditions of record card, data chart, printout, display, peripheral interface, data download communication protocol, standard communication protocol, test method of type approval, general safety protection indicators, and safety protection mechanism. According to the EU directive, it is compulsory to install a conforming digital recorder on any vehicle registered on and after August 5, 2004, in order to phase out traditional paper-reel recorders.

\section{The US}

In the 1970s, the NHTSA (National Highway Traffic Safety Administration) developed a tape recorder to analyze and save the collision data using analog signals. In 1997, the FMCSA (Federal Motor Carrier Safety Administration) turned its attention to EDR and began to collect the pre-accident and post-accident data recorded by EDR. The result showed that, after realizing the existence of EDR, a driver could significantly improve his driving habit and thus effectively prevent the occurrence of a collision. In October 1998, the FMCSA also joined the EDR Working Group established by the NHTSA. In 2006, the No. 49CFR563 regulation on EDR was promulgated in the Code of Federal Regulations and was expected to be implemented in 2010. But due to some reason, the regulation was amended in 2008 and its implementation time was postponed to 2013. The regulation includes 12 articles respectively dealing with the application, purpose, data \& parameters and data format of EDR.

\section{Domestic research on basic technical specifications of EDR}

The existing Chinese laws, regulations, rules, technical standards and documents directly concerning the vehicle traveling data recorder include: Road Traffic Safety Law and its Implementation Regulations, Provisions on the Application for and Use of Driving Licenses (issued by the Ministry of Public Security), GB/T19056-2003 Vehicle Travelling Data Recorder, GB7258-2004 Safety Specifications for Power-Driven Vehicles Operating on Roads, and others. All these have constituted the legal footing for application and supervision of vehicle traveling data recorders in our country. They, however, still need gradual improvement and refinement in many aspects such as the range of recorder-carrying vehicles and the requirements for to-be-installed products and their technologies, as most of them only propose or involve the popularization and application of the recorder. Therefore, this paper studies the technical specifications on event data recording and management, data format, data use, data post-processing and data function, thus increasing the efficiency of traffic accident management, optimizing the vehicle structure and road design and improving the traffic environment.

\section{Technical requirements for data items}

For every vehicle equipped with an EDR, all the data items in the Table 1 must be recorded according to the interval and frequency listed in the table. 
Tab. 1 Data items for all the vehicles with an EDR

\begin{tabular}{|c|c|c|}
\hline Data item & $\begin{array}{l}\text { Recording interval }{ }^{1} \\
(\text { relative to time } \\
\text { zero })\end{array}$ & $\begin{array}{l}\text { Data sample rate } \\
\text { (number of } \\
\text { samples per } \\
\text { second) }\end{array}$ \\
\hline Variation of longitudinal velocity & $0 \sim 250 \mathrm{~ms}$ & 100 \\
\hline Variation of maximum longitudinal velocity & $0 \sim 300 \mathrm{~ms}$ & Not applicable \\
\hline Time of variation of maximum velocity & $0 \sim 300 \mathrm{~ms}$ & Not applicable \\
\hline Indication speed of vehicle & $-5.0 \sim 0 \mathrm{~s}$ & 2 \\
\hline Throttle opening \% (displacement of accelerator pedal \%) & $-5.0 \sim 0 \mathrm{~s}$ & 2 \\
\hline Auxiliary brake, on/off & $-5.0 \sim 0 \mathrm{~s}$ & 2 \\
\hline Collision ignition circuit & $-0.1 \mathrm{~s}$ & Not applicable \\
\hline Data download ignition circuit & Download time & Not applicable \\
\hline Status of driver side belt & $-0.1 \mathrm{~s}$ & Not applicable \\
\hline Indicator lamp of frontal airbag, on/off & $-0.1 \mathrm{~s}$ & Not applicable \\
\hline $\begin{array}{l}\text { Deployment time of frontal airbag on the driver side (for } \\
\text { single-stage airbag); deployment time of first-stage airbag } \\
\text { (for multi-stage airbag) }\end{array}$ & Event & Not applicable \\
\hline $\begin{array}{l}\text { Deployment time of frontal airbag on the passenger side (for } \\
\text { single-stage airbag); deployment time of first-stage airbag } \\
\text { (for multi-stage airbag) }\end{array}$ & Event & Not applicable \\
\hline Multiple events, and number of events & Event & Not applicable \\
\hline Duration from event 1 to event 2 & If necessary & Not applicable \\
\hline Is the document recording completed (Y/N) & Following other data & Not applicable \\
\hline
\end{tabular}

1 Pre-collision data do not synchronize with collision data. The accuracy of pre-collision sampling time is required to be $-0.1 \sim 1.0$ s (for example, for $\mathrm{T}=-1$, the sampling time is $-1.1 \sim 0 \mathrm{~s}$ ).

Under the conditions listed in the column 2 of Table 2, all the data items in the column 1 of Table.2 must be recorded for every vehicle equipped with an EDR according to the interval and sample rate listed in the table.

Tab. 2 Data items of the vehicle under special conditions (example)

\begin{tabular}{|c|c|c|c|}
\hline Data item & Required condition & $\begin{array}{l}\text { Recording interval } \\
(\text { relative to time } \\
\text { zero })\end{array}$ & $\begin{array}{l}\text { Data sample rate } \\
\text { (number of } \\
\text { samples } \\
\text { second) }\end{array}$ \\
\hline Lateral acceleration & If recorded $^{2}$ & $0 \sim 250 \mathrm{~ms}$ & 500 \\
\hline Longitudinal acceleration & If recorded & $0 \sim 250 \mathrm{~ms}$ & 500 \\
\hline Normal acceleration & If recorded & $0 \sim 250 \mathrm{~ms}$ & 500 \\
\hline Variation of lateral velocity & If recorded & $0 \sim 250 \mathrm{~ms}$ & 100 \\
\hline $\begin{array}{l}\text { Variation of maximum lateral } \\
\text { velocity }\end{array}$ & If recorded & $0 \sim 300 \mathrm{~ms}$ & Not applicable \\
\hline $\begin{array}{l}\text { Time of variation of maximum } \\
\text { lateral velocity }\end{array}$ & If recorded & $0 \sim 300 \mathrm{~ms}$ & Not applicable \\
\hline $\begin{array}{l}\text { Time of variation of maximum } \\
\text { resultant velocity }\end{array}$ & If recorded & $0 \sim 300 \mathrm{~ms}$ & Not applicable \\
\hline Engine speed & If recorded & $-5.0 \sim 0 \mathrm{~s}$ & 2 \\
\hline Angle of vehicle rolling & If recorded & $-1.0 \sim 5.0 \mathrm{~s}^{3}$ & 10 \\
\hline ABS system (is it functioning) & If recorded & $-5.0 \sim 0 \mathrm{~s}$ & 2 \\
\hline $\begin{array}{l}\text { Stability control system (is it } \\
\text { functioning) }\end{array}$ & If recorded & $-5.0 \sim 0 \mathrm{~s}$ & 2 \\
\hline Input of steering wheel & If recorded & $-5.0 \sim 0 \mathrm{~s}$ & 2 \\
\hline $\begin{array}{l}\text { Status of passenger side belt (is } \\
\text { it locked) }\end{array}$ & If recorded & $-1.0 \mathrm{~s}$ & Not applicable \\
\hline
\end{tabular}




\begin{tabular}{|l|c|c|c|}
\hline $\begin{array}{l}\text { Status of suppression switch of } \\
\text { frontal airbag on the passenger } \\
\text { side (on, off, automatic) }\end{array}$ & If recorded & $-1.0 \mathrm{~s}$ & Not applicable \\
\hline $\begin{array}{l}\text { Time of stage- }{ }^{4} \text { deployment of } \\
\text { frontal airbag on the driver side }\end{array}$ & $\begin{array}{c}\text { If there is an airbag } \\
\text { with multi-stage } \\
\text { deployment on the } \\
\text { driver side }\end{array}$ & Event & Not applicable \\
\hline
\end{tabular}

${ }^{1}$ Pre-collision data do not synchronize with collision data. The accuracy of pre-collision sampling time is required to be $-0.1 \sim 1.0$ s (for example, for $T=-1$, the sampling time is $-1.1 \sim 0 \mathrm{~s}$ ).

"If recorded" means the data are recorded into a permanent memory for later download.

3“Angle of vehicle rolling” may be recorded at any time within -1.0 5.0s.

${ }^{4}$ This unit is recorded n-1 times, each corresponding to every grade of multistage airbag system.

\section{Technical requirements for data format}

The data items in Tables 1 and 2 must be recorded with the relevant range, sensitivity, and resolution and filter frequency, as shown in the Table 3.

Tab.3 Data record format (example)

\begin{tabular}{|c|c|c|c|c|}
\hline Data item & Range & Sensitivity & Resolution & $\begin{array}{c}\text { Filter } \\
\text { frequency }\end{array}$ \\
\hline Lateral acceleration & $-50 \mathrm{~g} \sim+50 \mathrm{~g}$ & $+/-5 \%$ & $0.01 \mathrm{~g}$ & $\begin{array}{c}\text { SAE } \\
\text { J211- }{ }^{1}, 60\end{array}$ \\
\hline Longitudinal acceleration & $-50 \mathrm{~g} \sim+50 \mathrm{~g}$ & $+/-5 \%$ & $0.01 \mathrm{~g}$ & $\begin{array}{c}\text { SAE } \\
\text { J211- } 1^{1}, 60\end{array}$ \\
\hline Normal acceleration & $-50 \mathrm{~g} \sim+50 \mathrm{~g}$ & $+/-5 \%$ & $0.01 \mathrm{~g}$ & $\begin{array}{c}\text { SAE } \\
\text { J211- } 1^{1}, 60\end{array}$ \\
\hline Variation of longitudinal velocity & $\begin{array}{l}-100 \mathrm{~km} / \mathrm{h} \sim \\
+100 \mathrm{~km} / \mathrm{h}\end{array}$ & $+/-5 \%$ & $1 \mathrm{~km} / \mathrm{h}$ & $\begin{array}{c}\text { Not } \\
\text { applicable }\end{array}$ \\
\hline Variation of lateral velocity & $\begin{array}{l}-100 \mathrm{~km} / \mathrm{h} \sim \\
+100 \mathrm{~km} / \mathrm{h}\end{array}$ & $+/-5 \%$ & $1 \mathrm{~km} / \mathrm{h}$ & $\begin{array}{c}\text { Not } \\
\text { applicable }\end{array}$ \\
\hline $\begin{array}{l}\text { Variation of maximum longitudinal } \\
\text { velocity }\end{array}$ & $\begin{array}{l}-100 \mathrm{~km} / \mathrm{h} \sim \\
+100 \mathrm{~km} / \mathrm{h}\end{array}$ & & $1 \mathrm{~km} / \mathrm{h}$ & $\begin{array}{c}\text { Not } \\
\text { applicable }\end{array}$ \\
\hline Variation of maximum lateral velocity & $\begin{array}{l}-100 \mathrm{~km} / \mathrm{h} \sim \\
+100 \mathrm{~km} / \mathrm{h}\end{array}$ & $+/-5 \%$ & & $\begin{array}{c}\text { Not } \\
\text { applicable }\end{array}$ \\
\hline $\begin{array}{l}\text { Time of variation of maximum } \\
\text { longitudinal velocity }\end{array}$ & $0 \sim 300 \mathrm{~ms}$ & $+/-3 \mathrm{~ms}$ & $2.5 \mathrm{~ms}$ & $\begin{array}{c}\text { Not } \\
\text { applicable }\end{array}$ \\
\hline $\begin{array}{l}\text { Time of variation of maximum lateral } \\
\text { velocity }\end{array}$ & $0 \sim 300 \mathrm{~ms}$ & $+/-3 \mathrm{~ms}$ & $2.5 \mathrm{~ms}$ & $\begin{array}{c}\text { Not } \\
\text { applicable }\end{array}$ \\
\hline $\begin{array}{l}\text { Time of variation of maximum resultant } \\
\text { velocity }\end{array}$ & $0 \sim 300 \mathrm{~ms}$ & $+/-3 \mathrm{~ms}$ & $2.5 \mathrm{~ms}$ & $\begin{array}{c}\text { Not } \\
\text { applicable }\end{array}$ \\
\hline Angle of vehicle rolling & $-1080^{\circ} \sim+1080^{\circ}$ & $+/-10^{\circ}$ & $10^{\circ}$ & $\begin{array}{l}\text { Not } \\
\text { applicable }\end{array}$ \\
\hline Indication speed of vehicle & $0 \mathrm{~km} / \mathrm{h} \sim 200 \mathrm{~km} / \mathrm{h}$ & $+/-1 \mathrm{~km} / \mathrm{h}$ & $1 \mathrm{~km} / \mathrm{h}$ & $\begin{array}{c}\text { Not } \\
\text { applicable }\end{array}$ \\
\hline Throttle opening & $0 \sim 100 \%$ & $+/-5 \%$ & $1 \%$ & $\begin{array}{c}\text { Not } \\
\text { applicable }\end{array}$ \\
\hline Engine speed & 0 10,000rpm & $+/-100$ rpm & 100rpm & $\begin{array}{c}\text { Not } \\
\text { applicable }\end{array}$ \\
\hline Auxiliary braking system, on/off & & $\begin{array}{c}\text { Not } \\
\text { applicable }\end{array}$ & On and off & $\begin{array}{c}\text { Not } \\
\text { applicable }\end{array}$ \\
\hline
\end{tabular}

\section{Technical requirements for data acquisition and reading}

Under the following conditions, the EDR must collect and record the data items of an event:

(1) In an airbag deployment collision, any previous collision records (including events) must be deleted. The deployment-related data must be collected and recorded, and the memory concerned must be locked to prevent future coverage of these data. 
(2) In a collision where the airbag hasn't been deployed but has reached the trigger threshold, all the EDR data saved previously must be deleted and the current data must be collected and recorded. In a case composed of two events, the end of first event shall be followed by the detection of where the second event begins.

\section{Acknowledgements}

This work was financially supported by the Fundamental Research Funds of China National Institute of Standardization titled Automotive Product Safety and Recall Technology Research Annual Report Compiled (No. 282014Y-3355).

\section{References}

[1] Xu Yang, Zhang Bao-ping, Shen Qing-hong. Design of Wireless Data Detection System of Vehicle Traveling Data Recorder[J]. Electronic Measurement Technologies, 2012(12) .

[2] Jiang Feng. ARM9-Based Design of Vehicle Traveling Data Recorder[J]. Automotive Engineer, 2014(1).

[3] Li Zhi-hong, Development of Vehicle Traveling Data Recorder with the Positioning Function[D]. North China Electric Power University, 2014.

[4] Shen Ming, Chen Yu-zhong, Lan Yan-fei, Wang Yan, Xu Shu-cai, Application and Standardization Prospect of Vehicle Event Data Recorder[J]. Standard Science, 2011(12).

[5] The first international general standard of motor vehicle accident data recorder is released[J]. Transportation Standardization, 2010(16). 